\title{
Integrated Ecosystem Sustainability Approach: Toward a Holistic System of Thinking of Managing Arid Ecosystems
}

\author{
Meshal M. Abdullah"1,2*, Amjad T. Assi ${ }^{3}$, Nasser B. Asadalla ${ }^{2,4}$ \\ ${ }^{1}$ Department Ecosystem Science and Management, Texas A\&M University, College Station, TX, USA \\ ${ }^{2}$ Natural Environmental Systems and Technologies (NEST) Research Group, Ecolife Sciences Research and Consultation, Kuwait City, Kuwait \\ ${ }^{3}$ Department Agriculture and Biological Engineering, Texas A\&M University, College Station, TX, USA \\ ${ }^{4}$ Public Authority of Agriculture Affairs and Fish Resources (PAAF), Al Rabya, Kuwait \\ Email: *meshal80@live.com
}

How to cite this paper: Abdullah, M.M., Assi, A.T. and Asadalla, N.B. (2019) Integrated Ecosystem Sustainability Approach: Toward a Holistic System of Thinking of Managing Arid Ecosystems. Open Journal of Ecology, 9, 493-505. https://doi.org/10.4236/oje.2019.911032

Received: September 28, 2019

Accepted: November 8, 2019

Published: November 11, 2019

Copyright $\odot 2019$ by author(s) and Scientific Research Publishing Inc. This work is licensed under the Creative Commons Attribution International License (CC BY 4.0).

http://creativecommons.org/licenses/by/4.0/

\section{(c) (i) Open Access}

\begin{abstract}
Ecosystems in arid regions play a pivotal role in providing services to vulnerable environments with considerable challenges including extreme temperatures, low precipitation, variable climate change, and infertile soil. The countries of the arid regions are facing more challenges due to land degradation, biodiversity loss, the scarcity of water and food resources, and protecting their inhabitant's public health. In many cases, policymakers in these countries are aware of the challenges, but they are seeking through scientific communities to develop clear sustainability and resiliency plans. Due to the complexity associated with arid ecosystem services, the scientist communities are still focusing on the development of integrated ecosystem management approaches. Within this line of commitment to our future generation, the paper in hand presents a framework for an Integrated Ecosystem Sustainability Approach (IESA). The core of this nexus approach is to understand and quantify the interlinkages between the ecosystem components, internal and external stresses, and society needs. The paper also identifies the key gaps to be considered when applying the IESA approach to arid ecosystem management plans.
\end{abstract}

\section{Keywords}

Integrated Ecosystem Sustainability Approach (IESA), Ecosystem Services, Arid and Semi-Arid Ecosystem, Ecosystem Complexity, Ecosystem Nexus

\section{Introduction}

The sustainability of natural resources is considered a global issue due to the in- 
crease in population, urbanization, economic pressure, and the increase in agriculture areas to cover society demand of water, energy, and food [1] [2] [3]. The demand for natural resources is adding additional pressure on the ecosystems, leading to more changes in land use/land cover. Several activities are negatively influencing the ecosystems through the increase in agriculture areas and crop production [4] [5], overgrazing [6] [7], and other recreational activities such as spring camping [8]. As a result of these activities, natural ecological systems are becoming more degradable, as well as, the ability of the ecosystem to continue providing the quality and quantity of ecosystem services for human well-being is harmfully affected [9] [10] [11].

With the increase in anthropogenic stresses on our ecosystems, many parts of the world are experiencing land degradation and desertification that affected their ecosystem services [12], and consequently affecting the human health [13]. Therefore, ecosystem restoration and management, as recognized globally, are becoming key components for long-term sustainability and strategic resilience planning. Particular attention should be given to arid ecosystems as they cover $41 \%$ of the earth's land surface and hold $38 \%$ of the human population [14] [15]. Arid ecosystems are dramatically influenced by the climate and anthropogenic activities that result in desertification, soil fertility loss, soil compaction, and consequently, loss of ecosystem services [16] [17]. Managing human activities and the uncertainties associated with climate change predictions are considered serious challenges for the management efforts of arid ecosystems [18].

The sustainability of the ecosystems is critical as these systems provide several services. These services include regulatory services (climate regulation, water quality and quantity), supporting services (ecosystem process, diversity maintenance, disturbance cycles), provisioning services (food, water, fiber, biochemical), and cultural services (culture identity, recreation and tourism) [19] [20]. In recent years, ecosystem services are becoming an active field of research as they provide food, fiber, and energy for human well-being [21]. To shed the light on the importance of ecosystem services, the Millennium Ecosystem Assessment (MA) was called by the United Nations Secretary-General Kofi Annan in 2000 to assess the consequences of ecosystem change and their impact on human wellbeing, and to enhance the conservation and sustainable use of those services through scientific bases for action needed [22]. However, the interlinkage between ecological diversity and ecosystem dynamics to ecosystem service underlying human well-being is poorly defined and quantified, and it was also unable to quantify uncertainties in many cases [23]. Such information is needed in order to understand the limits and consequences of ecosystem losses and the action required to maintain and restore ecosystem functions.

Consequently, the term of ecosystems was applied in different ways; for example, it was often used to describe the environment around a specific species or organisms. It was also used to describe land or aquatic areas [24]. Thus, all ecosystem terms and views are common and correct and need to be integrated. Also, less attention is given to the ecosystem services and management by decision 
policymakers. Therefore, managing natural ecological systems and their services is a challenge nowadays due to the complexity of these systems, and their connection with other management aspects including social, economics, governance, and policymaking. Several studies mentioned that these services have ecological, social, and economic underpinning [25] [26] [27] [28]. However, one of the significant challenges is that these three aspects are considered separately, even though they are analytically connected in the real world. Recently, more researches have been conducted to engage ecosystems in the nexus research [29], and how to send the right message to the decision makers [30]. This paper employs a new ecosystem management approach called the "Integrated Ecosystem Sustainability Approach (IESA)" which emphasis on understanding and quantifying the interlinkage between the abiotic including land (soils), water, and climate, as well as, the biota (organisms, plants, and animals). The approach also integrates the influence of external factors such as anthropogenic activities and climate change on ecosystem services. Considering the interlinkage between these components and factors is essential in landscape and ecological restoration planning and management. Understanding and quantifying these interlinkages provides a general understanding of the ecosystem function and lead to better ecosystem management and planning. IESA approach can play an important role in: 1) improving the quality of data methods and assessment modeling to assess the ecosystem function and the value of the ecosystem services to improve the efficiency of management and policy-making; 2) involving the beneficiaries of ecosystem services in research planning, governmental programs to enhance decision-makers' recommendations; 3 ) improve the restoration planning and long-term monitoring of the natural systems through the output tools and models, and 4) implementing interdisciplinary approaches which integrate the ecosystem elements including the land, abiotic, and climate.

\section{The Complexity of the Natural Ecosystem}

Ecologists have considerably improved our understanding of the ecological system due to the explanation of the observed patterns which presented the mix of dynamic processes that characters the trajectories of the ecological system [31]. Still, our current understanding of the complexity of the arid ecosystems does not allow a clear assessment of the interaction within the ecosystem elements, and of the impact of climate change on ecosystems in arid regions [32]. Most actions taken by decision-makers focused on solving one part of the system, which may end up declining other parts, leading to failure in managing and restoring ecological systems. It is also important to understand that restoration of disturbed ecosystems is costly, and that one restoration program is not suitable for all locations, it significantly depends on the type and degree of disturbance, and site condition [8] [33] [34].

In order to reach a more definitive conclusion, it is important to develop more holistic integrated approaches that focus on developing a better understanding of the interlinkages between the ecosystem components including the nexus of 
biota, and abiotic (land and climate). Therefore, it is important to create a holistic framework that defines and quantifies the relationships within these ecological elements and to determine the effects one has on the other.

\section{Integrated Ecosystem Sustainability Approach (IESA)}

This paper presents a proposed conceptual framework for the Integrated Ecosystem Sustainability Approach (IESA), as shown in Figure 1. IESA was designed to present a holistic way of thinking to focus on the interlinkages between the ecosystem elements, including biota, land, and climate, as well as, the external factors influencing the ecological system. IESA depends mainly on developing a quantitative characterization to the interlinkages and connections between the land, biota, and climate. These ecosystem elements are critically connected in multidirectional and complex ways, and through numerous sub-nexus as it is hard to ignore one element when managing others. This approach contains the relation between three major aspects which are significantly connected. The first aspect focuses on the interlinkages within the major ecosystem elements; the second is the anthropogenic aspects which include the social, economic and policies; and the third is the uncertainties aspects which include the climate change and its effects on the natural and social systems.

This approach will support decision makers in selecting appropriate decisions in protecting and managing their ecosystems and natural resources, as well as, the ecological restoration planning and management as it is considered one of the major issues due to the increase in land degradation and desertification in arid regions.

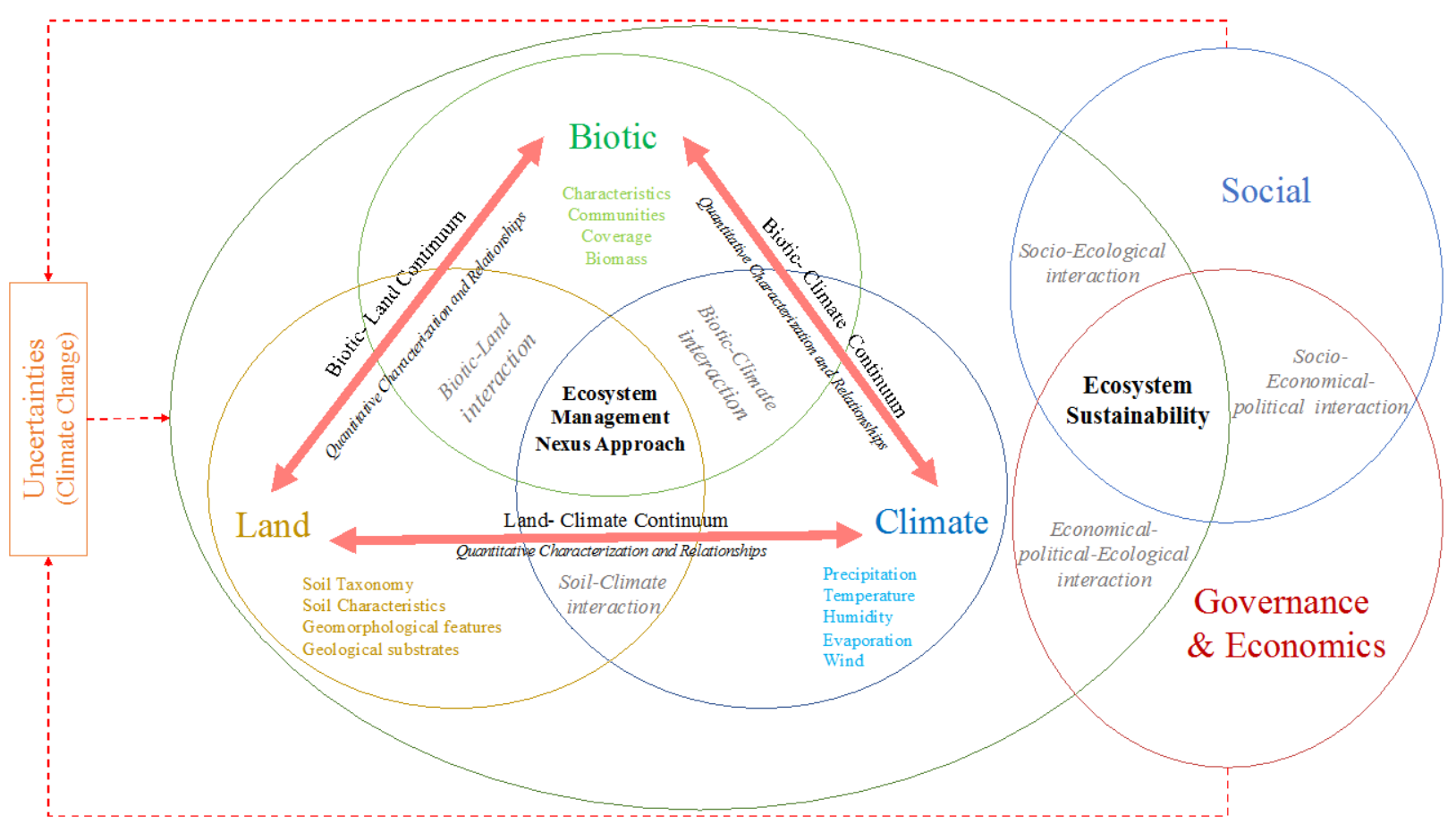

Figure 1. Integrated ecosystem sustainability approach (IESA). 


\subsection{The Nexus of the Ecosystem Elements}

The first dimension of the ecosystem elements in this approach covers the interlinkages between the biotic (vegetation, animals, and microorganisms) and the land (soil, geology, and topography). Biotic elements are also considered as sub-nexus, such that: plants, animals, and microorganisms are linked in several ways. Biotic and the lands are significantly connected, where plant communities are influenced by the soil type, salinity, and soil moisture [34]. Also, the topography of the land plays an important role in the distribution of vegetation coverage as low elevation land may contain a high amount of soil moisture content leading to more available water for plant uptake. Soil health including soil fertility, organic matter, bulk density, and texture plays a vital role in vegetation growth and survival, and in sustaining the global biosphere [35]. Vegetation also influences the amount of organic matter and phosphorus in the soil, as well as, accumulating and stabilizing the soil and sediment at the primary succession process [36]. Both biotic and abiotic factors can affect soil quality, which can significantly impact plant growth, productivity, and resistance to pests. Moreover, soil quality affects the interactions of plants with beneficial arthropods, such as plant-pollinators [15] [34].

The second dimension covers the interlinkages between biotic and the climate (including the temperature, water cycle, humidity, etc.). Metrological elements are crucial for plants growth and animal survival in arid regions. Evidence from previous studies showed that the vegetation-water interaction is considered one of the large importance in arid and semiarid lands [37]. Temperature and precipitation are essential resources for photosynthesis, which extremely influence the condition of the ecosystem [38]. The recovery of native vegetation highly depends on the temperature and rainfall quantity, intensity, and frequency [39]. Plants also are vital water and carbon reservoirs which are essential to some mammals, especially in arid systems with harsh weather and limited water resources. It was illustrated by several studies that the enhancement of soil quality and vegetation will support the water cycle through the reduction of runoff and erosion.

The relationship between the biotic and the abiotic factors in the ecosystem with climate can be viewed through the concept of phenology. The concept deals with the rhythmic interlinkages between the elements of the ecosystem and climate [40]. For example, birds may respond to climate change by shifting their breeding timing of the year. The birds may shift the timing of laying eggs in response to changes in weather and circadian rhythms [41]. In the GCC region, the climatic factors played a significant role in the development of plant communities [42]. This factor was used efficiently by the Asian Houbara Bustard Chlamydotis maqueenii [43] in Mahazat As-Sayd protected area to select specific habitat for specific purposes [44]. Furthermore, climate affected seasonal reproduction of small rodents [45].

The third ecological dimension in this approach focuses on the interlinkage 
between the climate and soils. Previous studies showed that the climate is influencing the soil quality and productivity. For example, high temperature decreases the water storage in the soil through the evaporation and evapotranspiration (ET) process [46]. The soil-water serves as a solvent and transporter of food nutrients for plant growth, acts as a nutrient itself, helps in chemical and biological activities of soil, and regulates soil temperature [47]. The soil forming processes and weathering, and the microorganisms also require water. The characteristics of soil organic matter mainly depend on the ecosystem condition such as soil-water saturation and temperature, which influence the quality of the plants, and the microbial communities [48]. Additionally, at extremely high temperatures of the desert ecosystems, soil layers can make suitable shelter microhabitats for birds as the hoopoe lark, Alaemon alaudipes and the spiny-tailed lizard, Uromastyx aegyptia microlepis [49] in a one-meter-deep burrow [50] [51].

\subsection{Anthropogenic Activities: Human Activities}

Ecosystem services provided by the ecological systems are negatively impacted by human activities. Therefore, the social-ecological system is a critical aspect that needs to be addressed in this approach. Previous work showed that human activities were the primary source of disturbance in the State of Kuwait [8]. For example, it was found that vegetation coverage was less than $5 \%$ in most of the desert areas in Kuwait before the second gulf war. Immediately after the liberation of the State of Kuwait, the vegetation coverage significantly increased as a result of the restrictions in entering these locations partially due to the landmine clearance operation from 1991-1998 where vegetation coverage reached 65\% respectively. After 1998 the vegetation coverage deteriorated again to reach $12 \%$ in 2002 after the areas were cleared from the landmines and human activities retook place, but vegetation coverage remained high at the protected areas [8]. This illustrates that the rapid increase in vegetation cover after the war was correlated with the protection of the desert, as well as, overgrazing and destructive camping are the major sources of disturbance.

The degradation of the ecosystem is also influenced by the rapid urbanization processes leading to more loses in the ecosystem services. Urbanization is considered a serious issue, especially in developing countries, as they create serious ecological and climatic problems in the ecosystem [52]. Unfortunately, urbanization planning has been poorly planned in most regions leading to series devastating consequences to the ecosystem and its services such as heat islands, therefore; there is an urgent need to consider the ecosystem services in the sustainable development planning [53] [54]. Further, it is time to look at the urban establishment as an ecosystem and recognize its components rather than narrowing it down to a land-use/land-cover concept.

The impacts of urban sprawl on the social dimension were not considered as they were in the economic and the environmental dimensions in the concept of 
sustainable development [55]. The exploitation of resources was more prioritized than the social value of native habitat [56]. At the beginning of the twentieth century, the rapid rates of urbanization led to the conversion of genuine ecosystems into novel engineered ecosystems to meet the demands of the growing populations. The social consequences of such transformation were least considered in the development of national plans in many countries in the Arabian Peninsula. Based on observations noted in the Bedouin society in Mahazat As-Sayd reserve in Saudi Arabia, the traditional knowledge and technologies that were inherited through generations eroded because of the influx of locals in urban settlements. There were significant differences realized between the old versus the young generations in terms of cherishing grazing lands, native plants, and the climate. Bedouins in the past were provided with their basic needs of food and water from their ambient ecosystems and their biotic and abiotic components. Members of the old generations were more linked than the young educated generations with the environment and were more friendly with it. The young local generations missed the chances of interacting with the ecosystem components due to the aggregation of the provisional services in the cities. Subsequently, the cultural services of the desert ecosystems were less valued by younger generations. This was reflected through the harmful practices of younger generations, as hunting and poaching, towards the biotic components.

Agriculture activities are also one of the important factors influencing the ecosystem services. Shifting natural ecosystems to agriculture areas to cover food demand, negatively affected the ecosystem services provided by the natural system [57]. Note, that this does not mean that we need to ignore agriculture, but it is essential to provide integrated methods, tools, and indicators that can help decision-makers in assessing the potential benefits of biodiversity and identify the tradeoffs among multiple ecosystems services.

Politics and economics are also important factors that need to be considered in social-ecological management. In restoration and rehabilitation of damaged ecosystems, ecologists may discuss the distribution of plants and animals and their relation to the ecosystem processes, as well as, the influence of human activities on the ecosystem structure and function unlike economists and politicians [58] [59]. The integration between these disciplines is an important concept as they are inextricably linked in the real world, but still continuing to be two separate disciplines. It also seems that the management of natural resources and ecosystems is a case-specific issue as policies and regulations play an active role in the disturbance of our ecosystem services. Therefore, one management or strategic plan may not be appropriate to all regions and countries since politics differ between countries and regions.

\subsection{Uncertainties: Climate Change}

Thirty years ago, the climate change issue was only a theory, but today, enough evidence is presented. The reports of the Intergovernmental Panel on Climate 
Change (IPCC) indicate that temperature has increased, and it is anticipated to increase further in the future unless serious actions are taken [60]. Such changes in the climate have serious direct and indirect impacts on the ecosystems in general, and specifically on the water cycle, biodiversity, and soil health. As the earth's temperature continues to rise, significant impacts occur on the freshwater supplies with the potential for devastating effects on these resources. Therefore, changes in temperature will affect the native species within the ecosystem directly and indirectly [61] [62]. As the temperature increase, evaporation and evapotranspiration rate will also increase leading to serious impacts on soil quality such as desertification and droughts, decrease in soil moisture, decrease in groundwater recharge, increase in soil salinity and changes in the annual runoff. In the last few decades, groundwater levels of many aquifers around the world showed a decreasing trend, which has significant impacts on the hydrological cycle leading to substantial effects on the soil and water quality and quantity [63].

Changes in temperature and precipitation may also have negative or positive feedback on the densities, distributions, and communities depending on the level of worming. It may also affect the species and biodiversity balance of grasses and woody vegetation [64]. Changes in precipitation will influence the soil moisture, which in turn will affect the vegetation density and productivity. Furthermore, the changes in rainfall will affect the structure and functions of animal communities. Such climate changes may also influence plant genetic composition and invite the invasive alien species as the site conditions become more hospitable to different alien species while native species become less competitive over their fundamental niche [65].

$\mathrm{CO}_{2}$ concentration is another serious global challenge. The decrease in native vegetation and soil health will significantly influence the $\mathrm{CO}_{2}$ sequestration in vegetation. Many plant communities act as a sink for the $\mathrm{CO}_{2}$ emissions as they sequestrate carbon emission (store carbon), which helps to balance carbon emissions. McHale, Hall [66] found that native desert shrubs in Arizona are the primary source of carbon pool and fluxes in the desert, and the trees are the dominant carbon pool in the cities. Therefore, the decrease in native desert shrubs will reduce the carbon pools (sink) leading to more carbon concentration. It was also illustrated by Bachelet, Neilson [67] that moderate increase in temperature in the United States produces a decrease in vegetation density and carbon sequestration across the country with limited changes in the type of vegetation. However, substantial increases in temperature will decrease the vegetation density and carbon sequestration with considerable shifting in vegetation communities.

\section{Identifying the Knowledge Gaps and Future Needed Research}

One major global challenge nowadays revolves around ecosystem sustainability. It is significant to identify the knowledge gaps in the tools, data, and models 
used in assessing the ecosystem. Therefore, more research is needed to focus on implementing the proposed integrated concept (IESA) that can help in integrating all common ecosystem terms and views, as well as, assessing the complexity of the ecosystems, and defining the direct and indirect external pressures (such as demographic, economic, sociopolitical, and cultural factors) on these ecosystems. This requires the development of a holistic approach which could consider all these elements, as well as, providing a quantitative characterization of the interlinkage within the ecosystem elements, and developing tools and indicators for each dimension within the proposed approach. In order to implement such approach and indicators, multidisciplinary researchers need to work together on implementing research in these areas at local, regional, and international levels. It also requires more interaction among institutions and their policy processes.

\section{Conclusion}

Integrated nexus approaches in the field of ecosystem management and services should gain increased importance in future research. The concept of the Integrated Ecosystem Sustainability Approach (IESA) presented in this paper emphasizes on understanding and quantifying the interlinkages between land, biotic (organisms, plants, and animals), and the climate, as well as, the influential external factors such as anthropogenic activities and climate change.

\section{Acknowledgements}

The authors would like to acknowledge KFAS, WEF nexus research group at Texas A\&M University, and NEST research group.

\section{Conflicts of Interest}

The authors declare no conflicts of interest regarding the publication of this paper.

\section{References}

[1] Karabulut, A.A., et al. (2018) A Proposal for Integration of the Ecosystem-WaterFood-Land-Energy (EWFLE) Nexus Concept into Life Cycle Assessment: A Synthesis Matrix System for Food Security. Journal of Cleaner Production, 172, 3874-3889. https://doi.org/10.1016/j.jclepro.2017.05.092

[2] Mohtar, R.H. and Daher, B. (2012) Water, Energy, and Food: The Ultimate Nexus. In: Encyclopedia of Agricultural, Food, and Biological Engineering, CRC Press, Taylor and Francis Group, Boca Raton.

[3] Ulgiati, S. and Brown, M.T. (1998) Monitoring Patterns of Sustainability in Natural and Man-Made Ecosystems. Ecological Modelling, 108, 23-36. https://doi.org/10.1016/S0304-3800(98)00016-7

[4] Ruhl, J. (2008) Agriculture and Ecosystem Services: Strategies for State and Local Governments. NYU Environmental Law Journal, 17, 424.

[5] Ruhl, J.B. (2000) Farms, Their Environmental Harms, and Environmental Law. Ecology Law Quarterly, 27, 263-349.

[6] Abril, A., Barttfeld, P. and Bucher, E. (2005) The Effect of Fire and Overgrazing 
Disturbes on Soil Carbon Balance in the Dry Chaco Forest. Forest Ecology and Management, 206, 399-405. https://doi.org/10.1016/j.foreco.2004.11.014

[7] Kauffman, J.B. and Krueger, W.C. (1984) Livestock Impacts on Riparian Ecosystems and Streamside Management Implications: A Review. Journal of Range Management, 37, 430-438. https://doi.org/10.2307/3899631

[8] Abdullah, M.M., et al. (2016) The Use of Remote Sensing to Develop a Site History for Restoration Planning in an Arid Landscape. Restoration Ecology, 24, 91-99. https://doi.org/10.1111/rec.12289

[9] Marichal, R., et al. (2017) Earthworm Functional Traits, Landscape Degradation and Ecosystem Services in the Brazilian Amazon Deforestation Arc. European Journal of Soil Biology, 83, 43-51. https://doi.org/10.1016/j.ejsobi.2017.09.003

[10] Yan, F., et al. (2016) The Effects of Spatiotemporal Changes in Land Degradation on Ecosystem Services Values in Sanjiang Plain, China. Remote Sensing, 8, 917. https://doi.org/10.3390/rs8110917

[11] Omar, S., et al. (2005) Land and Vegetation Degradation in War-Affected Areas in the Sabah Al-Ahmad Nature Reserve of Kuwait: A Case Study of Umm. Ar. Rimam. Journal of Arid Environments, 62, 475-490. https://doi.org/10.1016/j.jaridenv.2005.01.009

[12] Mahmoud, S.H. and Gan, T.Y. (2018) Impact of Anthropogenic Climate Change and Human Activities on Environment and Ecosystem Services in Arid Regions. Science of the Total Environment, 633, 1329-1344.

https://doi.org/10.1016/j.scitotenv.2018.03.290

[13] Chiabai, A., et al. (2018) The Nexus between Climate Change, Ecosystem Services and Human Health: Towards a Conceptual Framework. Science of the Total Environment, 635, 1191-1204. https://doi.org/10.1016/j.scitotenv.2018.03.323

[14] Aronson, J. and Alexander, S. (2013) Ecosystem Restoration Is Now a Global Priority: Time to Roll up Our Sleeves. Restoration Ecology, 21, 293-296. https://doi.org/10.1111/rec.12011

[15] Whisenant, S. (1999) Repairing Damaged Wildlands: A Process-Orientated, Landscape-Scale Approach. Vol. 1, Cambridge University Press, New York. https://doi.org/10.1017/CBO9780511612565

[16] Costantini, E.A., et al. (2016) Soil Indicators to Assess the Effectiveness of Restoration Strategies in Dryland Ecosystems. Solid Earth, 7, 397-414. https://doi.org/10.5194/se-7-397-2016

[17] Perrow, M.R. and Davy, A.J. (2002) Handbook of Ecological Restoration. Vol. 2, Cambridge University Press, Cambridge. https://doi.org/10.1017/CBO9780511549984

[18] Pires, A.P., et al. (2018) Interactive Effects of Climate Change and Biodiversity Loss on Ecosystem Functioning. Ecology, 99, 1203-1213. https://doi.org/10.1002/ecy.2202

[19] Chapin III, F.S., et al. (2010) Ecosystem Stewardship: Sustainability Strategies for a Rapidly Changing Planet. Trends in Ecology \& Evolution, 25, 241-249. https://doi.org/10.1016/j.tree.2009.10.008

[20] Naveh, Z. and Lieberman, A.S. (2013) Landscape Ecology: Theory and Application. Springer Science \& Business Media, Berlin.

[21] Council, N.R. (2012) Ecosystem Services: Charting a Path to Sustainability. National Academies, Washington DC.

[22] Duraiappah, A.K., et al. (1800) Ecosystems and Human Well-Being: Biodiversity 
Synthesis; A Report of the Millennium Ecosystem Assessment.

[23] Carpenter, S.R., et al. (2006) Millennium Ecosystem Assessment: Research Needs. Science, 314, 257-258. https://doi.org/10.1126/science.1131946

[24] Coulson, R.N., et al. (1999) Forest Landscapes: Their Effect on the Interaction of the Southern Pine Beetle and Red-Cockaded Woodpecker. Journal of Forestry, 97, 4-11.

[25] van Riper, C., et al. (2018) Incorporating Multilevel Values into the Social-Ecological Systems Framework. Ecology and Society, 23, 25. https://doi.org/10.5751/ES-10047-230325

[26] Hu, M., Zhang, J. and Huang, J. (2018) Assessing Social-Ecological System Resilience in Mainland China. Polish Journal of Environmental Studies, 27, 1085-1096. https://doi.org/10.15244/pjoes/76242

[27] Geneletti, D., Scolozzi, R. and Adem Esmail, B. (2018) Assessing Ecosystem Services and Biodiversity Tradeoffs across Agricultural Landscapes in a Mountain Region. International Journal of Biodiversity Science, Ecosystem Services \& Management, 14, 188-208. https://doi.org/10.1080/21513732.2018.1526214

[28] Ferreira, A., et al. (2018) A Social-Ecological Systems Framework as a Tool for Understanding the Effectiveness of Biosphere Reserve Management. Sustainability, 10, 3608. https://doi.org/10.3390/su10103608

[29] Fürst, C., Luque, S. and Geneletti, D. (2017) Nexus Thinking-How Ecosystem Services Can Contribute to Enhancing the Cross-Scale and Cross-Sectoral Coherence between Land Use, Spatial Planning and Policy-Making. International Journal of Biodiversity Science, Ecosystem Services \& Management, 13, 412-421. https://doi.org/10.1080/21513732.2017.1396257

[30] Stephan, R.M., et al. (2018) Water-Energy-Food Nexus: A Platform for Implementing the Sustainable Development Goals. Water International, 43, 472-479. https://doi.org/10.1080/02508060.2018.1446581

[31] Dakos, V. and Soler-Toscano, F. (2017) Measuring Complexity to Infer Changes in the Dynamics of Ecological Systems under Stress. Ecological Complexity, 32, 144-155. https://doi.org/10.1016/j.ecocom.2016.08.005

[32] García-Onetti, J., Scherer, M.E. and Barragán, J.M. (2018) Integrated and Ecosystemic Approaches for Bridging the Gap between Environmental Management and Port Management. Journal of Environmental Management, 206, 615-624. https://doi.org/10.1016/j.jenvman.2017.11.004

[33] Abdullah, M.M., et al. (2017) Will Autogenic Succession Be Sufficient to Recover from Vegetation Cover Loss or Will Soil Condition Need to Be Addressed in the Arid Lands of Kuwait? Arabian Journal of Geosciences, 10, 111. https://doi.org/10.1007/s12517-017-2911-6

[34] Bainbridge, D.A. (2007) A Guide for Desert and Dryland Restoration: New Hope for Arid Lands. Island Press, Washington DC.

[35] Jung, J., Philippot, L. and Park, W. (2016) Metagenomic and Functional Analyses of the Consequences of Reduction of Bacterial Diversity on Soil Functions and Bioremediation in Diesel-Contaminated Microcosms. Scientific Reports, 6, Article No. 23012. https://doi.org/10.1038/srep23012

[36] Van Hall, R., et al. (2017) Impact of Secondary Vegetation Succession on Soil Quality in a Humid Mediterranean Landscape. Catena, 149, 836-843. https://doi.org/10.1016/j.catena.2016.05.021

[37] Baudena, M. and Rietkerk, M. (2013) Complexity and Coexistence in a Simple Spatial Model for Arid Savanna Ecosystems. Theoretical Ecology, 6, 131-141. 
https://doi.org/10.1007/s12080-012-0165-1

[38] Báez, S., et al. (2013) Effects of Experimental Rainfall Manipulations on Chihuahuan Desert Grassland and Shrubland Plant Communities. Oecologia, 172, 1117-1127. https://doi.org/10.1007/s00442-012-2552-0

[39] Gong, Z., Zhao, S. and Gu, J. (2017) Correlation Analysis between Vegetation Coverage and Climate Drought Conditions in North China during 2001-2013. Journal of Geographical Sciences, 27, 143-160. https://doi.org/10.1007/s11442-017-1369-5

[40] Kreitzman, L. and Foster, R. (2010) Seasons of Life: The Biological Rhythms That Enable Living Things to Thrive and Survive. Profile Books.

[41] Helm, B., et al. (2013) Annual Rhythms That Underlie Phenology: Biological Time-Keeping Meets Environmental Change. Proceedings of the Royal Society B: Biological Sciences, 280, Article ID: 20130016. https://doi.org/10.1098/rspb.2013.0016

[42] Guoqing, L., et al. (2008) Effects of Ecological Factors on Plant Communities of Ziwuling Mountain, Shaanxi Province, China. Acta Ecologica Sinica, 28, 2463-2471. https://doi.org/10.1016/S1872-2032(08)60057-8

[43] Gray, J.E. (1832) Illustrations of Indian Zoology. Treuttel, Wurtz, Treuttel and Richter.

[44] Asadalla, N.B., et al. (2015) Assembly of Optimum Habitats for Asian Houbara Bustard (Chlamydotis macqueenii) in the Arabian Peninsula: The Vegetation Aspects. International Journal of Biodiversity, 2015, Article ID: 925093. https://doi.org/10.1155/2015/925093

[45] Bronson, F. (2009) Climate Change and Seasonal Reproduction in Mammals. Philosophical Transactions of the Royal Society B: Biological Sciences, 364, 3331-3340. https://doi.org/10.1098/rstb.2009.0140

[46] Reynolds, J.F., Kemp, P.R. and Tenhunen, J.D. (2000) Effects of Long-Term Rainfall Variability on Evapotranspiration and Soil Water Distribution in the Chihuahuan Desert: A Modeling Analysis. Plant Ecology, 150, 145-159. https://doi.org/10.1023/A:1026530522612

[47] Plaster, E. (2013) Soil Science and Management. Cengage Learning, Boston.

[48] Gobat, J.-M., Aragno, M. and Matthey, W. (2004) The Living Soil: Fundamentals of Soil Science and Soil Biology. Science Publishers, Rawalpindi.

[49] Blanford, H.F. (1875) On the Age and Correlations of the Plant-Bearing Series of India, and the Former Existence of an Indo-Oceanic Continent. Quarterly Journal of the Geological Society, 31, 519-542. https://doi.org/10.1144/GSL.JGS.1875.031.01-04.41

[50] Williams, J.B., Tieleman, B.I. and Shobrak, M. (1999) Lizard Burrows Provide Thermal Refugia for Larks in the Arabian Desert. The Condor, 101, 714-717. https://doi.org/10.2307/1370208

[51] Wilms, T.M., et al. (2010) Aspects of the Ecology of the Arabian Spiny-Tailed Lizard (Uromastyx aegyptia Microlepis Blanford, 1875) at Mahazat as-Sayd Protected Area, Saudi Arabia. Salamandra, 46, 131-140.

[52] Wan, H., et al. (2015) Selective Grazing and Seasonal Precipitation Play Key Roles in Shaping Plant Community Structure of Semi-Arid Grasslands. Landscape Ecolo$g y$, 30, 1767-1782. https://doi.org/10.1007/s10980-015-0252-y

[53] Eigenbrod, F., et al. (2011) The Impact of Projected Increases in Urbanization on Ecosystem Services. Proceedings of the Royal Society B: Biological Sciences, 278, 3201-3208. https://doi.org/10.1098/rspb.2010.2754 
[54] Dobbs, C., Kendal, D. and Nitschke, C.R. (2014) Multiple Ecosystem Services and Disservices of the Urban Forest Establishing Their Connections with Landscape Structure and Sociodemographics. Ecological Indicators, 43, 44-55. https://doi.org/10.1016/j.ecolind.2014.02.007

[55] Tisdale, H. (1941) The Process of Urbanization. Social Forces, 20, 311. https://doi.org/10.2307/3005615

[56] Ma, L., et al. (2014) Impacts of Urban Expansion on Nitrogen and Phosphorus Flows in the Food System of Beijing from 1978 to 2008. Global Environmental Change, 28, 192-204. https://doi.org/10.1016/j.gloenvcha.2014.06.015

[57] Nanni, A. and Grau, H. (2017) Land-Use Redistribution Compensated for Ecosystem Service Losses Derived from Agriculture Expansion, with Mixed Effects on Biodiversity in a NW Argentina Watershed. Forests, 8, 303.

https://doi.org/10.3390/f8080303

[58] Edwards, P.J. and Abivardi, C. (1997) Ecological Engineering and Sustainable Development. In: Restoration Ecology and Sustainable Development, Cambridge University Press, Cambridge, 325-352.

[59] Paletto, A., Giacovelli, G. and Pastorella, F. (2017) Stakeholders' Opinions and Expectations for the Forest-Based Sector: A Regional Case Study in Italy. International Forestry Review, 19, 68-78. https://doi.org/10.1505/146554817820888654

[60] Zhao, Y. and Yu, Z. (2012) Vegetation Response to Holocene Climate Change in East Asian Monsoon-Margin Region. Earth-Science Reviews, 113, 1-10. https://doi.org/10.1016/j.earscirev.2012.03.001

[61] Rosenzweig, C. and Tubiello, F. (1997) Impacts of Global Climate Change on Mediterranean Agrigulture: Current Methodologies and Future Directions. An Introductory Essay. Mitigation and Adaptation Strategies for Global Change, 1, 219-232. https://doi.org/10.1007/BF00517804

[62] Santos, J.A., et al. (2016) Understanding Climate Change Projections for Precipitation over Western Europe with a Weather Typing Approach. Journal of Geophysical Research: Atmospheres, 121, 1170-1189. https://doi.org/10.1002/2015JD024399

[63] Mengistu, D., Bewket, W. and Lal, R. (2016) Conservation Effects on Soil Quality and Climate Change Adaptability of Ethiopian Watersheds. Land Degradation \& Development, 27, 1603-1621. https://doi.org/10.1002/ldr.2376

[64] Huang, J., et al. (2017) Dryland Climate Change: Recent Progress and Challenges. Reviews of Geophysics, 55, 719-778. https://doi.org/10.1002/2016RG000550

[65] Zhao, D. and Feng, P. (2015) Temperature Increase Impacts Personality Traits in Aquatic Non-Native Species: Implications for Biological Invasion under Climate Change. Current Zoology, 61, 966-971. https://doi.org/10.1093/czoolo/61.6.966

[66] McHale, M.R., et al. (2017) Carbon Lost and Carbon Gained: A Study of Vegetation and Carbon Trade-Offs among Diverse Land Uses in P Hoenix, Arizona. Ecological Applications, 27, 644-661. https://doi.org/10.1002/eap.1472

[67] Bachelet, D., et al. (2004) Regional Differences in the Carbon Source-Sink Potential of Natural Vegetation in the USA. Environmental Management, 33, S23-S43. https://doi.org/10.1007/s00267-003-9115-4 